\title{
On Paths for Non-Profit Organizations Participating in Family Services and Supports in China
}

\author{
Le PEI \\ Management College of Bohai University, Jinzhou, Liaoning, China \\ p982262@126.com
}

\begin{abstract}
Keywords: Family Services and Supports, Non-Profit Organizations, Participate, Construction of Capabilities, Social Services.
\end{abstract}

\begin{abstract}
In new era, there are theoretical and practical needs for non-profit organizations to participate in family services and supports in China. To guarantee the effect of social services, non-profit organizations should reinforce the construction of capabilities in professional services, internal governance, communication and public relations. On the basis of precise orientation, different types of non-profit organizations will make best use of their advantages to seek suitable paths to participate in family services and supports to fulfill positive functions.
\end{abstract}

\section{Introduction}

In 21st century, non-profit organizations become important actors and take more and more functions of social services, in which participating family services and supports is feasible and effective. The United States of American has long history of servicing and supporting families, there are famous non-profit organizations as Charitable Organization Clubs(1887), Family Service Association of America(1911), American Institute of Family Relations(1930), and National Alliance for Family Life(1972) [1]. In China, non-profit organizations participating family services and supports means a series of non-profit actions to provide social services and outside supports by physical and the spiritual methods, the aim is to improve social welfare and supple social security, the emphasis is to help families and individuals in real and potential difficult position. The effects of non-profit organizations participating family services and supports are complex. The family members' deviations in mentality, cognition and actions can be corrected to keep healthy. The conflicts can be solved to promote stability of family elements. The Cultural and spiritual environment can be optimized to expand social net and accumulate positive energy.

\section{Analysis on Functions and Demands for Non-Profit Organizations Participating in Family Services and Supports}

The focus of non-profit organizations participating in family services and supports are to achieve family and society harmony by providing the fundamental and necessary family services that individuals can't afford. The degree of involvement and types of actions of non-profit organizations participating in family services and supports are different, but needs of all actors really exist.

\section{Functions of Non-profit organizations in Family Services and Supports}

Remedy: Government can't take into account every field all the time. Under official acquiescence or without any legal permission, non-profit organizations dominate in some fields of family services and supports to meet ignored social needs that are not covered by policies. Most grass non-profit organizations depend on this to gain legitimacy, but not all non-profit organizations have motivation and flexibility.

Assist: In the field dominated by government, non-profit organizations become major partner. Non-profit organizations provide kinds of services directly, or just be the contractor of government 
procurement to improve the amount, level and standard of services. These non-profit organizations are most legal organizations, and have official background.

Lead: By the authorization and support from government, non-profit organizations probe suitable methods and content of participating in family services and supports. Official and grass non-profit organizations accumulate experiences, and provide information and advices to government. The limitations of structure and administration make official organizations less flex and creative than grass organizations.

\section{Demands of Society, Government and Non-Profit Organizations}

To society, Social change makes different family structures, functions and relations. Now, Chinese social security has been built up totally. But, vulnerable groups always exist, for the reasons of externality, non-market operation, policies weakness and poverty [2]. The factors, which include limitation of resources and policies, social change, abilities of individuals and families, make family services and supports can't meet different social needs, especially for specific groups and fields. These should not be ignored, social problems will arise if be handled incorrectly. The third sector besides market and government -- non-profit organization, can meet the needs of family services and supports by more practical and effective means.

To government, it is an important part of policy process improvement and social management innovation that permitting and encouraging non-profit organizations to participate in family services and supports. The government's goals consist of reforming structure and functions of social security, raising the level of social welfare, reducing financial pressure, etc. So, the government should recognize the functions and abilities of non-profit organizations fully to allocate resources rationally. Guidance, direct cooperation and services purchase can be used to provide opportunities and supplies to make non-profit organizations the positive partners and powerful assistants. Then, the pressures of microcosmic management and social conflict caused by directed governance can be alleviated.

To non-profit organizations, participating family services and supports is a major path to serve society and fulfill organization purposes. Non-profit organizations provide many types of family services and supports, which will expand individual social net and accelerate diversified growth, and create broad space for their development. Non-profit organizations will strengthen social security by meeting needs of specific field and vulnerable groups. When seeing the outcome of Non-profit organizations' actions, other actors will accept and praise. Non-profit organizations will enlarge influence, gain more supports from society and government, and strengthen their abilities. Then, positive interaction can be built.

\section{Construction of Abilities for Non-Profit Organizations Participating in Family Services and Supports}

The construction of abilities is the basis and center for non-profit organizations to participate in family services and supports, while services effect is the guarantee, acceptance of social and government is the standard. The construction of abilities should include three aspects.

\section{Construction of Professional Service Abilities}

The professional service abilities are integrated individual (full-time members and volunteers) and organizational abilities leaded by social needs. The index always takes into account indicators such as theory basis, knowledge system, training and performance, morality and ethics [3]. The professional service abilities consist of services abilities facing objects and services abilities facing members. They involve needs analysis, design and decision making, project procession and finance, information and technology, communication and creation. Under the general structure, the services combination list and personnel training and development plan should be made. At the same time, non-profit organization should transform into learning organization to adapt to changing circumstances. After graded by authorities, adjust and progress must be made continuously. Meanwhile, instruments, technologies and 
services should be renewed. Various social needs should be predicted and analyzed more accurately and efficiently, and meet by perfect and customized services. Services procession should be optimized to serve society more effectively.

Complete donation collect techniques and channel are important for non-profit organizations to construct service abilities. Especially in vital field and part, non-profit organizations get finance, material, projects, procurement and contracts. But, these are limit. Following the trend, non-profit organizations must improve skills and optimize revenue structure to raise more money outside government. Collect channels, techniques and skills should be more flexible. Besides enterprises and foundations, non-profit organizations should classify public welfare market deeply to get more resources. The cooperation between non-profit organizations and industry associations, trade organizations, supporting foundations should be conventional. United donation should be used to reduce disturb to donators. Collection forms could be annual donation, letter and e-mail donation, phone call donation and personal request. Apps and electronic payment help to find more potential donators. Virtual coupon may be used to supplement direct donation. New model of donation - investment will bring more interest, and bring win to all of non-profit organizations, donators, government and society.

\section{Construction of Inner Governance Abilities}

Non-profit organizations must be non-profit, and obey laws. Organization orientations, rights and obligations should be defined. Procession should be under the chapter. Procedures of decision making, personnel, finance, project management and routine operation should be specified. The chapter consists of organization mission and goals, interest conflicts avoidance, rational resources use. Information about mission, goals, values, mechanism, activities, functions and so on, should be announced publicly. Decision making, organization management and financial budget must be under control. The core of moral standard is serving the public. Motivations also should be applied to keep morality, profession and efficiency of full-time members and volunteers. Coordination with others helps to prevent illegal behaviors.

Governance structure of non-profit organization involves congress, council, (execution) committee and supervisors, all of which work together. The main principals are simplification and efficiency, when inner parts are adjusted or set up. There are represents of members, volunteers and interest parties in congress, which make fatal decisions thoroughly. Council make routine decisions and take responsibilities, members of council should have processional knowledge and be impartial. Committee executes decisions, which composes by development (plan or donation) department, human resource department, public relations department, finance management department. Supervisors, who report to and managed by congress directly, supervise all the process of council's decision making and committee's execution.

\section{Construction of Communication and Public Relations Abilities}

Following network era and knowledge economy, non-profit organizations should accelerate informatization. Publicity, share and response connect non-profit organizations, government, communities and the public. Non-profit organizations join government's strategic plan through entrust, coordination and participation. Development platform should be built under the macro-control of government, which is the communication node of services buyer, supplier and accepter. Non-profit organizations group to cluster and upgrade functions. With communities, non-profit organizations collect, analyze and share information, and attract more community volunteers and older volunteers. The information provided by non-profit organizations must be real and reliable. The cost should be kept in a low level. Projects should improve public welfare and cover more. Non-profit organizations should be audited and take responsibilities for their operation.

There is little competition among Chinese non-profit organizations, so systemic appraisal and supervision are necessary to keep transparent. Scientific rules and procedures are the points to build good customer relationship and organization image, while communication instruments and pattern should be appropriate. In decision making, ameliorate PERT to ensure decision quality and total effect. 
In project process, priority evaluation emphasizes on relativity and appropriateness to allocate resources. The appraisal indicators should be comprehensive and balanced, the structure includes non-profit and values, allocation and process, efficiency and effectiveness of resources absorbency, social acceptance and satisfaction. Modern governance structure defines boundary of rights and responsibility, and requests professional management and positive organization culture. Non-profit organizations should be open to welcome direct or indirect supervisions over entry, process and quit, by government, donators, beneficiary, media, industry associations, trade organizations, the public and interest parties. Renewed management techniques, such as funds and finance management, time management, project management, quality management, will encourage innovation and promote services.

\section{Operation of Non-Profit Organizations Participating in Family Services and Supports}

With changing of structures of consumption and industries and increasing of civil and rural revenue, social demands are becoming sundry and complex. This not only provides spaces and opportunities for non-profit organizations to participate in family services and supports, but also brings challenges and requirements. So, non-profit organizations must understand modern family structure, family relation and family life cycle accurately to respond family needs actively. Non-profit organizations will find suitable paths by building new family support system [4]. Social groups participate in family services and supports by means of propaganda, organization, support, assistance, etc. People-run non-enterprise units participate in family services and supports by means of providing services and goods indirectly. Foundations participate in family services and supports by means of support, hatch, etc. They should start with fields that needed by society urgently to build service brand and promote family harmony and society harmony.

Family medical and health care services and supports: non-profit organizations will organize knowledge lectures, door clinics and family practices, which may help family to prevent and cure common diseases and chronic diseases.

Family pension services and supports: in less sub type of aging society, the olds of lack of social relationship who have no social security, the ability to work, and legal custody, should get extra security. Non-profit organizations will provide home care, shopping and delivery, housework, maintenance, spiritual consolation, leisure and entertainment, etc [5].

Family education and training services and supports: including public popularization of knowledge and vocational training, marriage and birth education, parenting education, growth and socialization education, etc.

Family nursing and behavior cultivation services and supports: day care facing children and old people belongs to home nursing, while emotional guidance, psychological adjustment and behavior modification belong to behavior cultivation.

Family aid services and supports: treatment and donation to material and mental illnesses, free information consultation and legal assistance belong to economic aid, while mediation to family conflicts and neighborhood disputes and deathbed care belong emotional aid.

Acceptances and approvals from outside actors and society are necessity for non-profit organizations to participate in family services and supports. The government should plan the total development of non-profit organizations, interact with non-profit organizations by more supporting policies. Communities should enhance collaboration with non-profit organizations by public coupons, subsidies and services bank, to accelerate innovations. Industry associations and trade organizations communicate and share with non-profit organizations by self services and management. It can be predicted that non-profit organizations will fruitfully participate in family services and supports, and Chinese dream will come true soon. 


\section{Acknowledgement}

Thanks Shu LI for help and support to this research.

\section{References}

[1] Guang-liang YUAN, On American Family Social Work and Revelation to China, Theory Monthly, 2012, 179-182.

[2] Li-li HAN, Problems Occurred in Families and Intervention of Social Work into It, Journal of Capital Normal University (Social Sciences Edition), 2005, 98-102.

[3] Garvin, C. D. \& Tropman, J. E. Social Work in Contemporary Society, Englewood Cliffs: Prentice - Hall. 1992, 457-464.

[4] Fang ZHAO, Family Social Work: Its Origin, Nature and Development, Journal of Guang Dong University of Technology (Social Sciences Edition), 2013, 53-57.

[5] Yi-peng TIAN, The Old Groups and Construction of Civic Publicity, Fu Jian Forum, 2011, 191-196 